\title{
Dynamic Regulation of cpg15 during Activity-Dependent Synaptic Development in the Mammalian Visual System
}

\author{
Roderick A. Corriveau, ${ }^{1}$ Carla J. Shatz, ${ }^{1}$ and Elly Nedivi ${ }^{2}$ \\ ${ }^{1}$ Howard Hughes Medical Institute and Department of Molecular and Cell Biology, University of California at Berkeley, \\ Berkeley, California 94720, and ${ }^{2}$ Center for Learning and Memory, Department of Brain and Cognitive Sciences, \\ Massachusetts Institute of Technology, Cambridge, Massachusetts 02139
}

During visual system development, neural activity regulates structural changes in connectivity including axonal branching and dendritic growth. Here we have examined a role for the candidate plasticity gene 15 (cpg15), which encodes an activity-regulated molecule that can promote dendritic growth, in this process. We report that cpg15 is expressed in the cat visual system at relatively high levels in the lateral geniculate nucleus (LGN) but at very low levels in its synaptic target, layer 4 of the visual cortex. Prenatally, when cpg 15 mRNA in the LGN is most abundant, expression is insensitive to action potential blockade by tetrodotoxin. Postnatally, activity regulation of cpg15 emerges in the LGN coincident with development of ocular dominance columns in the visual cortex. cpg15 can be detected in layers $2 / 3$ and $5 / 6$ of visual cortex postnatally, and expression in layers $2 / 3$ is activity-regulated during known periods of activity-dependent plasticity for these layers. Localization and regulation of $c p g 15$ expression in the visual system are consistent with a presynaptic role for CPG15 in shaping dendritic arbors of target neurons during activity-dependent synaptic rearrangements, both in development and adulthood.

Key words: visual system; cpg15; lateral geniculate nucleus; dendritic growth; visual cortex; neuron
During the final phases of visual system development, adult patterns of neuronal connectivity are achieved via an activitydriven process of synaptic rearrangement (for review, see Constantine-Paton et al., 1990; Shatz, 1990; Goodman and Shatz, 1993; Katz and Shatz, 1996). Neuronal activity profoundly influences the growth of axonal terminals, contributing to their final size, form, and restriction to characteristic postsynaptic locations (Shatz and Stryker, 1978; LeVay et al., 1980; Meyer, 1982; Reh and Constantine-Paton, 1985; Stryker and Harris, 1986). Less is known about how neural activity ultimately shapes dendritic morphology. Rapid effects on spine and filopodia structure can be seen in vitro after changes in activity levels or induction of long-term potentiation (Engert and Bonhoeffer, 1999; MaleticSavatic et al., 1999; McKinney et al., 1999). There are indications that during development elaboration of dendritic arbors is also regulated by input activity (Tieman and Hirsch, 1982; Katz and Constantine-Paton, 1988; Lund et al., 1991; Bodnarenko and Chalupa, 1993; Kossel et al., 1995; Rocha and Sur, 1995; Rajan and Cline, 1998), but results vary. Several reports suggest that blocking NMDA receptor-mediated synaptic transmission can increase dendritic growth (Rocha and Sur, 1995; McAllister et al., 1996), whereas others report the opposite (Vogel and Prittie, 1995; Rajan and Cline, 1998). In visual cortex, the action of

\footnotetext{
Received June 25, 1999; accepted June 30, 1999.

This work was supported by National Institutes of Health Grants EY02858 to C.J.S. and EY11894 to E.N. and by an Alcon Research Institute Award to C.J.S. who is an Investigator of the Howard Hughes Medical Institute. We thank Sandra Wiese and Cynthia Cowdrey for excellent technical assistance, Ed Lein for the feline BDNF probe, and Dr. Hollis Cline for critical reviewing of this manuscript and helpful discussions.

Correspondence should be addressed to Dr. Elly Nedivi, Department of Brain and Cognitive Sciences, Massachusetts Institute of Technology, 50 Ames Street, E18670, Cambridge, MA 02139.

Dr. Corriveau's present address: Department of Anatomy and Cell Biology, Wayne State University School of Medicine, 540 East Canfield, Detroit, MI 48201. Copyright (C) 1999 Society for Neuroscience $0270-6474 / 99 / 197999-10 \$ 05.00 / 0$
}

neurotrophins on dendritic growth requires neural activity (McAllister et al., 1996). In some cases, action potential blockade with tetrodotoxin (TTX) does not affect dendritic development but can affect spine density (Dalva et al., 1994; Kossel et al., 1997).

At the cellular level, little is known about molecular mechanisms underlying activity-evoked axonal and dendritic remodeling. In recent years, forward genetic screens using adult models for synaptic plasticity have identified activity-regulated candidate molecules whose function could mediate activity-dependent modification of neuronal structure (Nedivi et al., 1993; Qian et al., 1993; Link et al., 1995; Lyford et al., 1995; Tsui et al., 1996). Some of these molecules are also expressed in the developing brain (Nedivi et al., 1993; Lyford et al., 1995; Tsui et al., 1996), consistent with the hypothesis that there may be overlap between mechanisms of developmental and adult plasticity (Kandel and O’Dell, 1992). Candidate plasticity gene 15 (cpg15), a 115 amino acid glycosylphosphatidylinositol-linked cell surface protein (Naeve et al., 1997), was identified in the hippocampus after experimentally induced seizure (Nedivi et al., 1993). cpg15 was subsequently found to be expressed at high levels during postnatal cortical development and also regulated by light-driven neural activity in the adult rat visual cortex (Nedivi et al., 1996). During development in Xenopus, CPG15 protein staining is present in tectal cells and is intense in retinal ganglion cell (RGC) axons within the optic tract and tectal target area (Nedivi et al., 1998). When overexpressed in the Xenopus retinotectal system in vivo, CPG15 promoted exuberant dendritic arbor growth in developing tectal neurons (Nedivi et al., 1998). These observations suggest that endogenous CPG15 on both pre- and postsynaptic sides of the retinotectal synapse may be available to promote dendritic arbor elaboration of developing tectal neurons.

To investigate further a role for CPG15 in activity-dependent synaptic changes during development, we examined cpg15 expres- 
sion and regulation in the cat visual system at times when two of the best-studied examples of developmental plasticity occur: segregation of RGC axonal arbors into eye-specific laminae in the lateral geniculate nucleus (LGN) of the thalamus and segregation of LGN axons into ocular dominance columns (ODCs) within layer 4 of primary visual cortex (Hubel and Wiesel, 1970; LeVay et al., 1978; Shatz and Stryker, 1978, 1988; Shatz, 1983; Shatz and Kirkwood, 1984; Sretavan and Shatz, 1986; Stryker and Harris, 1986; Sretavan et al., 1988; Penn et al., 1998; Hata et al., 1999). The timing, location, and regulation of cpg15 expression in the visual system are consistent with a role in translating neural activity into structural rearrangements in connectivity.

\section{MATERIALS AND METHODS}

Animal manipulations and tissue isolation. All surgical procedures for the prenatal manipulations, including osmotic minipump perfusions of TTX, have been described previously (Shatz, 1983; Shatz and Stryker, 1988; Campbell et al., 1997; Corriveau et al., 1998) and were approved by the University of California Berkeley Animal Care and Use Committee.

For intraocular injections of TTX postnatally, anesthesia was induced and maintained by isoflurane $/ \mathrm{O}_{2}$ via mask. Topical ophthaine (Choice Medical Supplies) was applied to the eye in preparation for injection. A sterile solution of TTX (or vehicle) was injected over a period of 1-2 min into the posterior chamber of the eye using a 30 gauge needle attached to a $10 \mu \mathrm{l}$ Hamilton syringe via silastic tubing. After the eye injection was complete, the kitten recovered from anesthesia under observation. Monocular activity blockade was maintained by injecting the right eye every $48 \mathrm{hr}$ for the duration of the manipulation; e.g., for blockade from postnatal day 89 (P89) to P99, TTX was injected on P89, P91, P93, P95, and P97. For younger animals, amounts of $3 \mathrm{~mm}$ TTX administered per injection were as follows: P6-P11, $2 \mu \mathrm{l}$; P20-P23, $2.5 \mu \mathrm{l}$; P38, $3 \mu \mathrm{l}$; P40, $3.5 \mu \mathrm{l}$; P40-P46, $4 \mu \mathrm{l}$; and P60-P64, $8 \mu \mathrm{l}$. For older animals (P89-P99 and adult), 7 ul of 5 mM TTX per injection was used. Vehicle-injected controls received equivalent volumes of vehicle solution (sodium citrate buffer, $\mathrm{pH} 4.8$ ): $18.6 \mathrm{~mm}$ citrate for younger animals and $31 \mathrm{~mm}$ citrate for the older animals. Tissue was obtained for in situ hybridization as described above.

Cloning of feline cpg15. Total RNA was extracted from P22 cat visual cortex with an acid guanidinium thiocyanate-phenol-chloroform mixture as described previously (Chomczynski and Sacchi, 1987). Poly $\left(\mathrm{A}^{+}\right)$ RNA was selected by a standard oligo-dT-cellulose method (Sambrook et al., 1989). First-strand cDNA synthesis was primed using an oligo-dT$X b a \mathrm{I}$ primer adaptor (Promega, Madison, WI) and superscript II RNase H-reverse transcriptase (Life Technologies, Gaithersburg, MD) according to the manufacturers' instructions except that 5-methyldeoxycytidine $5^{\prime}$-triphosphate (5-Me dCTP) and trace amounts of $\left[{ }^{32} \mathrm{P}\right] \mathrm{dCTP}$ replaced standard dCTP. After alkaline hydrolysis of mRNA and removal of unincorporated nucleotides by a G-50 column and precipitation, polyA tailing of first-strand cDNA was performed using terminal transferase (Promega). Second-strand cDNA synthesis was by Klenow (Boehringer Mannheim, Indianapolis, IN) and primed using the oligo-dT-XbaI primer adaptor (Promega). After phenol $/ \mathrm{ChCl}_{3}$ extraction and precipitation, double-stranded cDNA was resuspended, digested with $X b a \mathrm{I}$ (Life Technologies), phenol/ChCl3-extracted, precipitated, resuspended, and size-selected on a Sephacryl S-500 HR cDNA size fractionation column (Life Technologies). Several fractions were selected, and T4

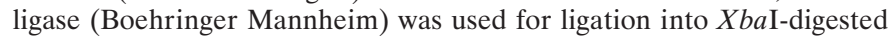
and calf alkaline phosphatase (Stratagene, La Jolla, CA)-treated ZAP express vector (Stratagene). Ligated DNA was packaged using Gigapack III gold packaging extract (Stratagene); 600,000 independent plaqueforming units were obtained and amplified. In a sampling experiment, 16 of 16 phage selected had inserts that could be released by $X b a \mathrm{I}$ digestion, with an average insert size of $2.3 \mathrm{~kb}$.

By the use of a $450 \mathrm{bp}$ cDNA probe containing the coding region of rat cpg15, $5 \times 10^{5}$ plaques of the above library were screened by conventional filter lifts hybridized at medium stringency (Sambrook et al., 1989). A $1.5 \mathrm{~kb}$ cDNA containing the entire feline cpg15-coding region was isolated. Partial sequencing determined that at the nucleotide level, the coding region of feline cpg15 is $\sim 94 \%$ identical to that of rat cpg15. A 750 bp EcoRI/Xcm fragment was subcloned into pBSK-, appropriately linearized, and used as a template to generate ${ }^{35} \mathrm{~S}$-labeled riboprobes for in situ hybridization.
Further details regarding cDNA library construction and feline cpg15 cloning are available on request.

In situ hybridization. In situ hybridization was performed as described (Simmons et al., 1989). Cryostat sections $(12 \mu \mathrm{m})$ were cut, air dried, fixed for $30 \mathrm{~min}$ in sodium phosphate-buffered $4 \%$ paraformaldehyde, dehydrated with ethanol, and stored at $-80^{\circ} \mathrm{C}$. Sections were thawed, permeabilized by proteinase $\mathrm{K}$ treatment, acetylated, dehydrated with ethanol, and hybridized at $57^{\circ} \mathrm{C}$ for $12-15 \mathrm{hr}$ with riboprobe labeled with ${ }^{35} \mathrm{~S}-\mathrm{UTP}(1250 \mathrm{Ci} / \mathrm{mmol}$; Dupont NEN, Boston, MA). The sections were then incubated with $50 \mu \mathrm{g} / \mathrm{ml}$ RNase A for $30 \mathrm{~min}$ at $37^{\circ} \mathrm{C}$ and then washed with a series of SSC solutions; the highest stringency wash was $0.1 \times \mathrm{SSC}, 60^{\circ} \mathrm{C}$ for $30 \mathrm{~min}$. After exposure to Kodak XAR-5 film at room temperature, sections were coated with NTB-2 emulsion and developed after 7-10 d. For negative controls, hybridization of radiolabeled feline cpg15 antisense probe was specifically eliminated by competition with a 10,000-fold excess of nonradiolabeled antisense cRNA, resulting in only background levels of silver grains.

The feline BDNF probe was a gift from Ed Lein.

Quantitative data analysis. Data were analyzed by scanning each slide under dark-field illumination with a Diagnostics Instruments Spot Camera. The images were saved in TIFF file format and opened in NIH Image (version 1.62b7), and the relevant area was quantified (black $=255$ and white $=0$ ). Pixel gray scale values were converted to a brightness scale by subtracting the resulting value from 255 . Background values were obtained (taken over either a nonhybridizing region of the section or the slide itself; both regions giving essentially identical readings) and subtracted out to yield net signal.

Developmental results (see Fig. 3 for summary) are based on mean signal \pm SEM for all slides run in two separate experiments that analyzed independent sets of animals; within a given run, sections from all ages were processed simultaneously. To allow compilation of the two experiments, we normalized data within each run to a value obtained for the signal in the superficial layers of visual cortex at the oldest age examined. The ages of the animals used and the number of sections examined (not including negative controls) are presented below as follows: age (number of animals, number of sections). First experiment: embryonic day 43 (E43) (1, 4), E52 (1, 3), P0 (1, 3), P10 (1, 4), P25 (1,3), P40 (1, 4), and P91 (1, 4). Second experiment: E52 (2, 4 and 4), P11 (1, 5), P22 (1, 4), P42 (1, 4), and P96 (1, 4). For clarity of presentation, small age differences between postnatal animals in the first and second experiments are not noted in the figure (i.e., P10 + P11, P25 + P22, P40 + P42, and P91 + P96). A third experiment that included slides from most of the animals used for the first two experiments confirmed the results shown (see Fig. 3).

For comparison of feline cpg15 signals obtained from control versus activity-blocked LGNs (prenatal manipulations) or control and activityblocked eye-specific layers (postnatal manipulations), slides were scanned, and the net signal was calculated as above. In the case of the prenatal LGN $\pm \mathrm{TTX}$, one control and one activity-blocked section were mounted on each slide, and a ratio of the signals was obtained in a pairwise manner. In two separate experiments including three sets of pairwise comparisons (TTX and vehicle, TTX and citrate, and TTX and citrate), for a total of six animals and 11 slides, mean \pm SEM for $\mathrm{TTX} /$ control $=1.16 \pm 0.10$; i.e., no significant difference was observed. For postnatal manipulations, ratios of signal between control and activity-blocked eye-specific layers were calculated within sections, and the resulting ratios were averaged across sections. These data are presented (see Fig. 6) with each column representing data from a separate animal. Note that an identical analysis was performed for LGNs ipsilateral to the blocked eye (data not shown), yielding results indistinguishable from those presented for the contralateral analysis. Statistical analysis was performed by equal-tails $t$ tests.

Fluctuations in feline cpg15 signal in primary visual cortex layers $2 / 3$ were quantified as follows. Dark-field images were imported from microscope slides as above. By the use of NIH Image, the TIFF images were first smoothed $(3 \times 3)$, and the pixel brightness values along a line parallel to the pial surface approximately midway between the bottom of layer 1 and the top of layer 4 were exported to SuperScope II and processed with a low-pass filter $(\mathrm{fc}=10 \%)$ twice. Data were plotted versus distance (see Fig. $6 \mathrm{~B}$ ) using Microsoft Excel. Distances measured from midtrough to midtrough for monocular TTX-treated animals are (mean \pm SEM): P40-P43, $1049 \pm 45 \mu \mathrm{m}$; P61-P64, $1190 \pm 71 \mu \mathrm{m}$; and P90-P92, $1353 \pm 46 \mu \mathrm{m}$, values very close to the expected width for two ocular dominance columns $(\sim 1 \mathrm{~mm})$. 
E43

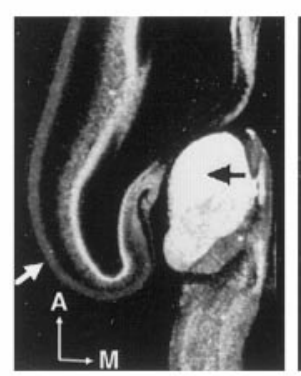

P25

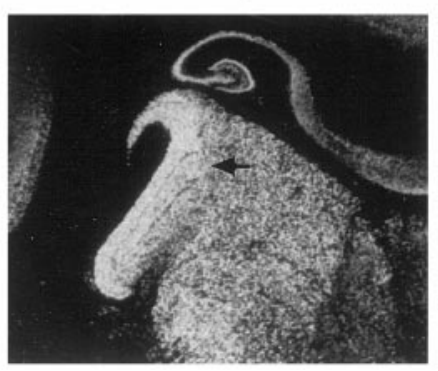

E52
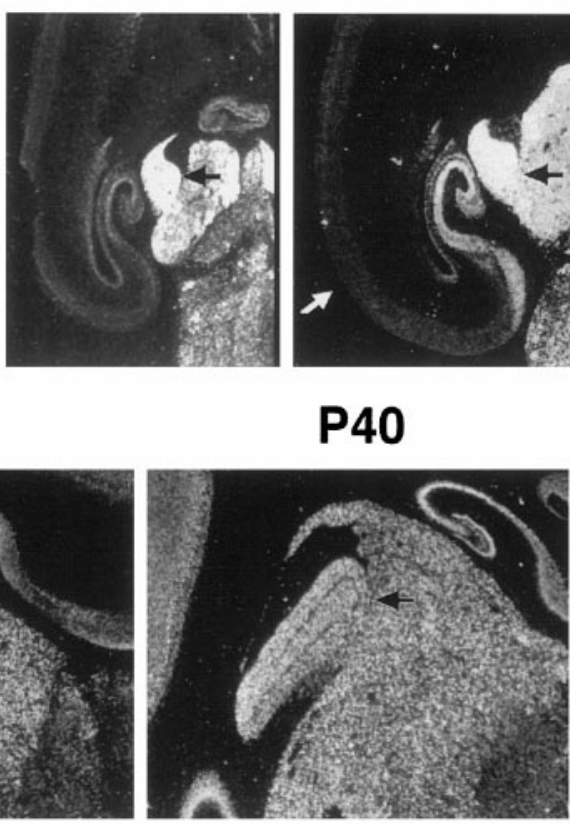

Po

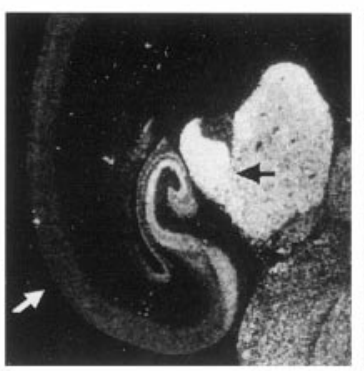

P10

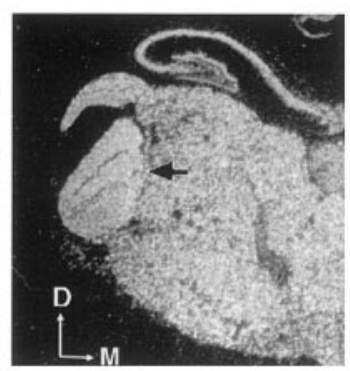

P91

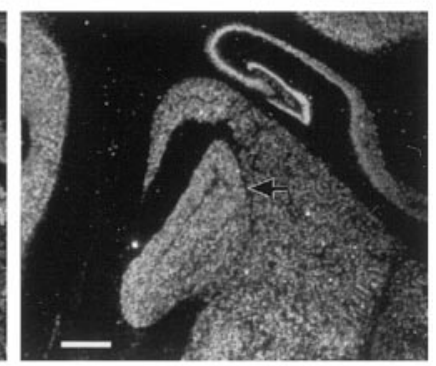

Figure 1. Regulation of feline cpg15 mRNA expression in the LGN during normal development. In situ hybridization (using an ${ }^{35} \mathrm{~S}$-labeled antisense riboprobe) was performed on brain sections at the level of the LGN (black arrows) from animals of the indicated ages. Results are presented in dark field. Sections were cut either in the horizontal [E43, E52, P0; anterior $(A)$ and medial $(M)$ are indicated] or coronal [P10, $\mathrm{P} 25, \mathrm{P} 40, \mathrm{P} 91$; dorsal $(D)$ and $M$ are indicated] plane. The white arrow in E43 and $\mathrm{PO}$ is the visual cortex. Scale bar, $1 \mathrm{~mm}$.

\section{RESULTS}

Expression of cpg15 in the LGN and visual cortex of the cat during normal development and through maturation of adult connectivity was characterized by in situ hybridization. Next, to distinguish between activity-independent and -dependent modes of cpg15 regulation during development, we investigated the effect of TTX-induced activity blockade on cpg15 mRNA levels at developmental times when neural activity is required for the formation of appropriate synaptic connections in the visual system.

\section{Developmental regulation of cpg15 expression}

cpg15 mRNA is present in LGN neurons throughout development and in the adult. cpg15 expression is highest at the earliest time point examined (E43), when RGC axons have entered the LGN but are not segregated into eye-specific layers. cpg15 mRNA levels in LGN neurons remain high through E52, the peak of the period for RGC axon segregation into eye-specific layers in the LGN, until P0 when eye-specific layer formation in the LGN is virtually complete (Shatz, 1983) (Fig. 1). Although postnatal expression levels of cpg15 in the LGN continue to decrease until P10, they remain relatively high into adulthood (P91; Fig. 1), long after activity-dependent synaptic rearrangement of the retinogeniculate projection is complete (Dubin et al., 1986; Shatz and Stryker, 1988; Sretavan et al., 1988).

Within the developing visual cortex, cpg 15 mRNA is present at low levels prenatally in the differentiating cortical plate (Fig. 1). By P10, when the majority of LGN axons have grown into layer 4 from the subplate (Shatz and Luskin, 1986), cpg15 can be detected in the superficial and deep layers of cortex (Fig. 2). Signal continues to increase in these layers throughout LGN axon segregation into ODCs in layer 4 (P20-P40; Fig. 2). cpg15 expression is undetectable in layer 4 at birth (P0; Fig. 1). It is first detectable in layer 4 at $\mathrm{P} 40$, near the completion of ODC formation, but at very low levels that are maintained in mature layer 4 (Fig. 2).

To characterize these results quantitatively, we obtained images of tissue sections after autoradiography with a digital cam- era, and signal intensity was expressed as units of pixel gray values. The examples shown in Figures 1 and 2 are representative of the combined quantitative results summarized in Figure 3. Quantitative analysis shows that $\operatorname{cpg} 15$ mRNA levels in the LGN progressively decrease with age, until P10 when they stabilize at their adult level. Conversely, from P10, cpg15 mRNA levels in the superficial and deep layers of cortex gradually increase with age. The onset of cpg15 expression in layer 4 is delayed with respect to that in other cortical layers, and levels are significantly lower. In both the LGN and visual cortex (as in the hippocampus-see Fig. 2), cpg15 expression is maintained well into maturity.

\section{Activity-dependent regulation of $\operatorname{cpg} 15$}

cpg15 expression in the LGN is unaltered by blockade of $\mathrm{Na}^{+}$dependent action potentials at the earliest times examined in prenatal development (Fig. 4A). Action potential blockade was achieved by minipump infusion of TTX into the ventricle of fetal cats between E42 and E52 (birth is E65), a time when spontaneous retinal waves drive ganglion cells and LGN neurons to fire $\mathrm{Na}^{+}$-dependent action potentials (Meister et al., 1991; Wong et al., 1995; Mooney et al., 1996; Penn et al., 1998) and are required for LGN axons to segregate into eye-specific layers (Penn et al., 1998). Even immediately after birth, monocular injections of TTX between P6 and P11 did not alter cpg15 expression in LGN layers receiving input from the injected eye (Fig. 4B). To confirm that activity had indeed been blocked in the injected eye, we examined the expression of BDNF, known to be regulated by activity in many structures. BDNF expresses at low levels in the LGN at early ages and increases steadily as development proceeds (E. Lein, A. Hohn, and C. J. Shatz, personal communication). Monocular blockade between P6 and P11 clearly decreases BDNF expression in LGN layers receiving input from the TTXtreated but not vehicle-treated eye in the same experiment in which there was no detectable regulation of cpg15 (Fig. 4B).

Monocular TTX injections at progressively later ages starting at P20 decrease but do not abolish completely cpg15 expression in LGN layers innervated by the blocked eye (Figs. 5, 6). Regulation 


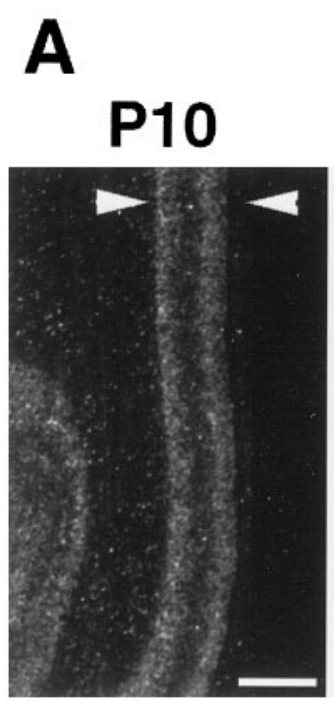

P40
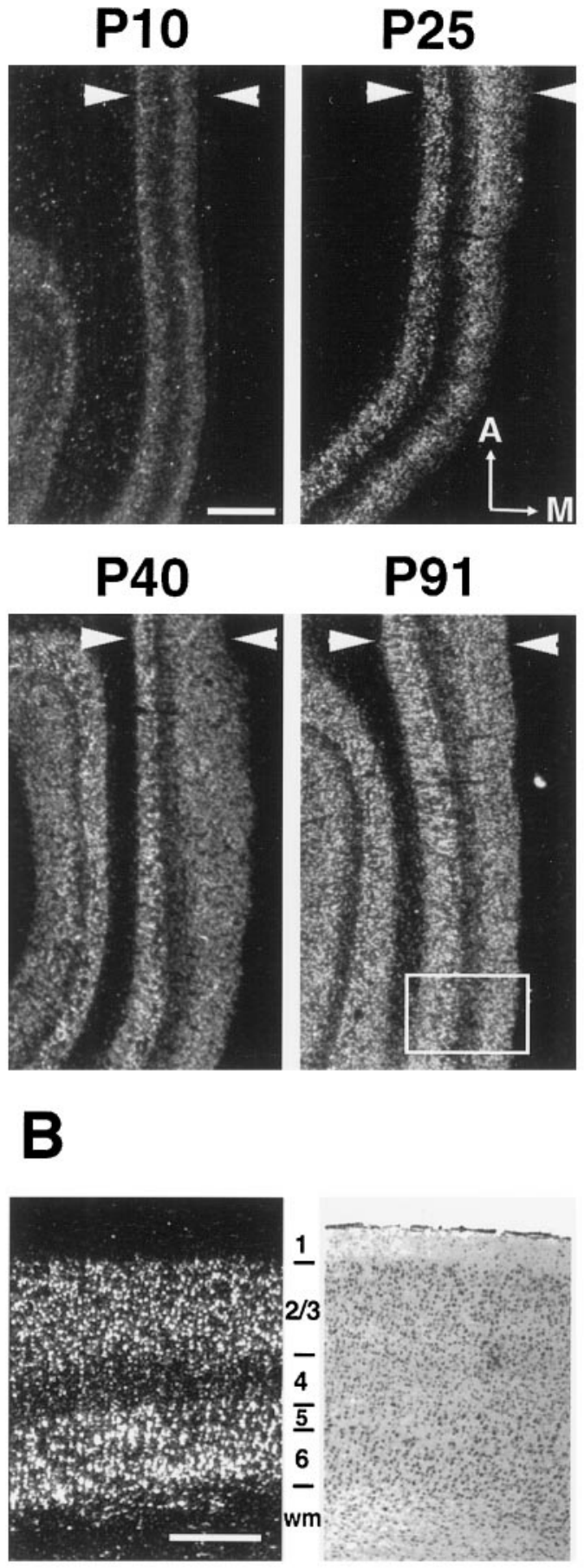

P91

Figure 2. Regulation of feline cpg15 mRNA expression in the primary visual cortex during normal development. In situ hybridization was performed as described in Figure 1. A, Horizontal sections of visual cortex, with arrowheads delimiting the cortical plate. Results are presented in dark field. The boxed area indicates the approximate region shown in $B$. Anterior $(A)$ and medial $(M)$ are indicated. $B$, High magnification of feline cpg15 in situ hybridization signal at P91 (dark field, left) and the image of an adjacent cresyl violet-stained section (bright field, right). Note that the vast majority of signal is found in layers $2 / 3,5$, and 6 . The pial surface is $u p$. wm, White matter. Scale bars: $A, 1 \mathrm{~mm} ; B, 0.5 \mathrm{~mm}$.

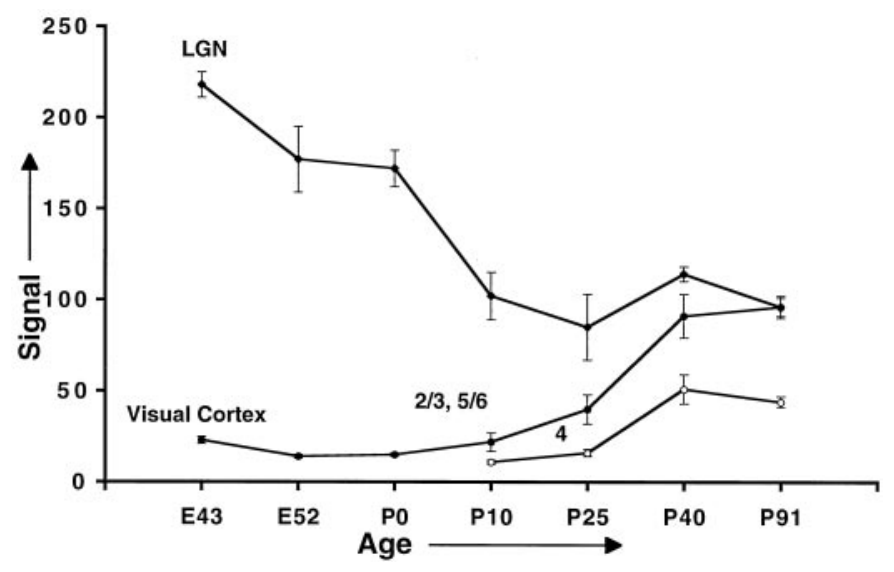

Figure 3. Feline cpg15 mRNA levels decrease in the LGN (filled diamonds) and increase in primary visual cortex (filled and open circles) during development. Error bars represent the SEM for 7-11 determinations (slides) obtained in two independent experiments, except for the $\mathrm{E} 43$ and $\mathrm{P} 0$ values, which are based on analysis of 4 and 3 determinations, respectively. Because results obtained for layers $2 / 3$ and $5 / 6$, quantified separately, were essentially identical, the numbers presented are only for layers $2 / 3$ ( filled circles).

of cpg15 expression by activity in the LGN persists throughout and beyond the critical period for segregation of geniculocortical afferents into ODCs in the cortex and continues after maturation of adult patterns of thalamocortical connectivity as documented quantitatively in the histograms of Figure 6. These data indicate that initially cpg15 is not regulated by action potential activity in the LGN. Later in development, coincident with the critical period for activity-dependent segregation of LGN axons within layer 4 of visual cortex, the levels of cpg15 expression in the LGN decline, and a significant fraction becomes sensitive to regulation by activity.

A possible concern is that the decrease in levels of cpg15 expression in LGN layers receiving input from the blocked eye is caused by cell shrinkage of LGN neurons and a general decrease in protein synthesis as a consequence of the well known competition with active eye inputs within layer 4 of cortex during the critical period (Hubel and Wiesel, 1970; Guillery, 1972). However, several observations argue strongly that shrinkage alone cannot account for the decrease in cpg15 mRNA levels. First and most notably, similar decreases in cpg15 expression occur at P90 and even in adults (Figs. 5, 6), long after the period of susceptibility of LGN neurons to shrinkage caused by monocular eye closure. Second, $10 \mathrm{~d}$ monocular TTX blockades result in a downregulation of cpg15 expression virtually identical to those produced by 3 d blockades (P40-P43 and P38-P48 in Fig. 6), whereas LGN cell shrinkage and effects on ocular dominance after monocular eye closure are known to increase with length of closure (Hubel and Wiesel, 1963). Finally, levels of BDNF mRNA in the same animals are much more dramatically affected by monocular TTX injections than are those of cpg15 (P38-P48 TTX and P38-P48 TTX BDNF in Fig. 6), indicating that expression of these two genes can be regulated differentially. This observation would not be expected if there were simply an overall decline in metabolism. Thus, we conclude that at least some if not all of the decrease in cpg15 mRNA is caused by an activitydependent regulation of gene expression.

Within primary visual cortex, no effect of monocular TTX injections could be detected within layer 4 at any age, consistent 


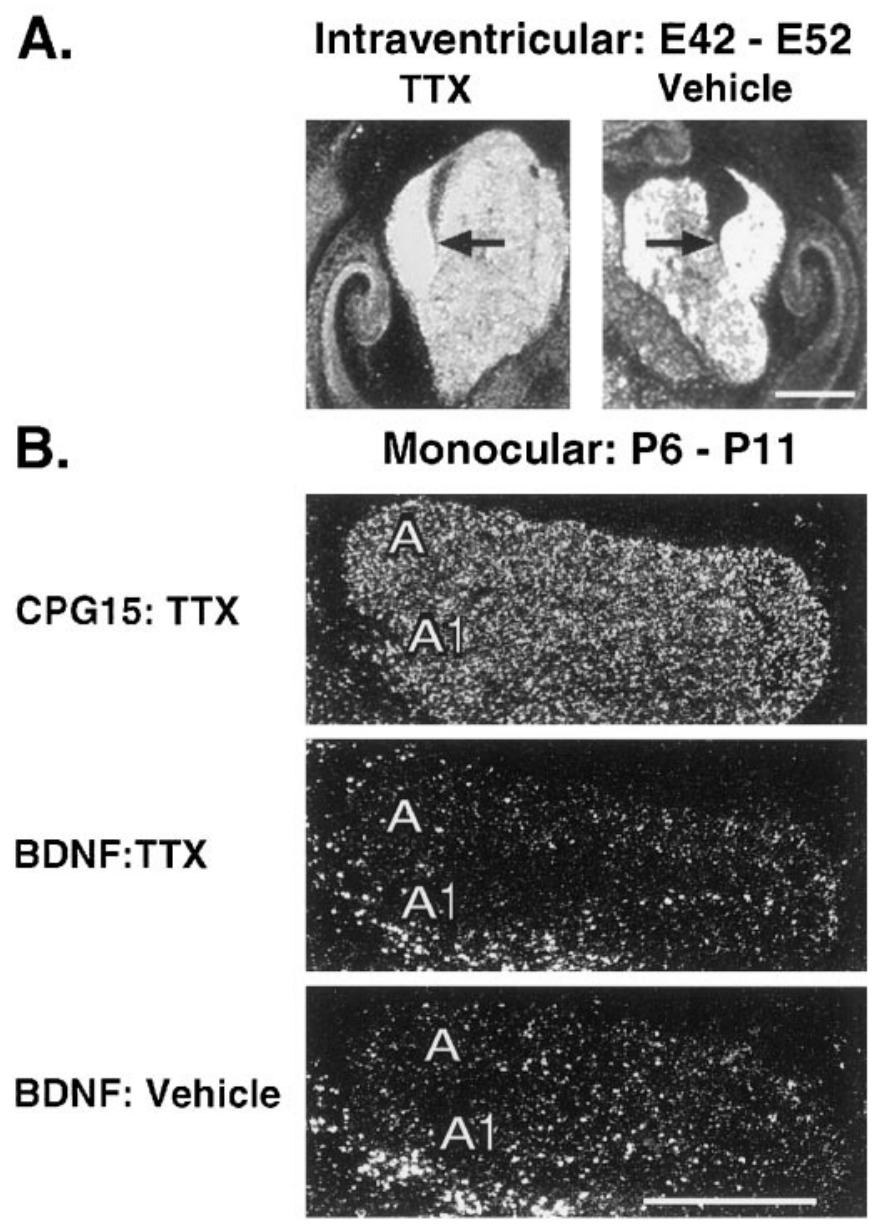

Figure 4. Prenatal and early postnatal analyses of feline cpg15 regulation by endogenous neural activity in the LGN. $A$, In situ hybridization demonstrates little if any change in feline cpg 15 mRNA levels in the prenatal LGN after $10 \mathrm{~d}$ (E42-E52) of intracranial application of the voltage-gated sodium channel blocker TTX. Black arrows indicate LGNs. $B$, Top, After $5 \mathrm{~d}$ of monocular TTX applied to the right eye between P6 and P11 (data shown for right LGN), the feline cpg15 signal remains unchanged in the eye-specific LGN layer corresponding to the blocked eye (layer A1; compare with control layer A). Middle, On an adjacent section BDNF mRNA levels decreased in layer A1, demonstrating that a successful activity blockade had been achieved. Bottom, Moreover, in an animal treated in parallel with vehicle only, BDNF mRNA levels remain unchanged in layer A1 (injection in right eye; right LGN shown). Note that at this time in development BDNF mRNA levels are low in the LGN. Scale bars, $1 \mathrm{~mm}$.

with the very low level of cpg15 signal there throughout life. However, as ocular dominance columns form in layer 4, the activity of all cortical neurons within a given column, including those located in layers $2 / 3$ and to a lesser extent layers 5/6, comes to be dominated by one eye (Hubel and Wiesel, 1977; Shatz, 1990; Katz and Shatz, 1996). By P40, anatomical segregation of LGN axons into ODCs within layer 4 is nearing completion (LeVay et al., 1978; Antonini and Stryker, 1993). We therefore examined cpg15 expression patterns in layers $2 / 3$ and 5/6 after brief periods of monocular TTX injections at P40 or later (Fig. 7, top). Such injections between $\mathrm{P} 40$ and $\mathrm{P} 43$ resulted in periodic fluctuations in cpg15 signal intensity in cortical layers $2 / 3$. To examine whether these fluctuations might correspond to ocular dominance columns driven by the TTX-treated (low-intensity signal) versus the active (high-intensity signal) eyes, we quantitated signal variation along

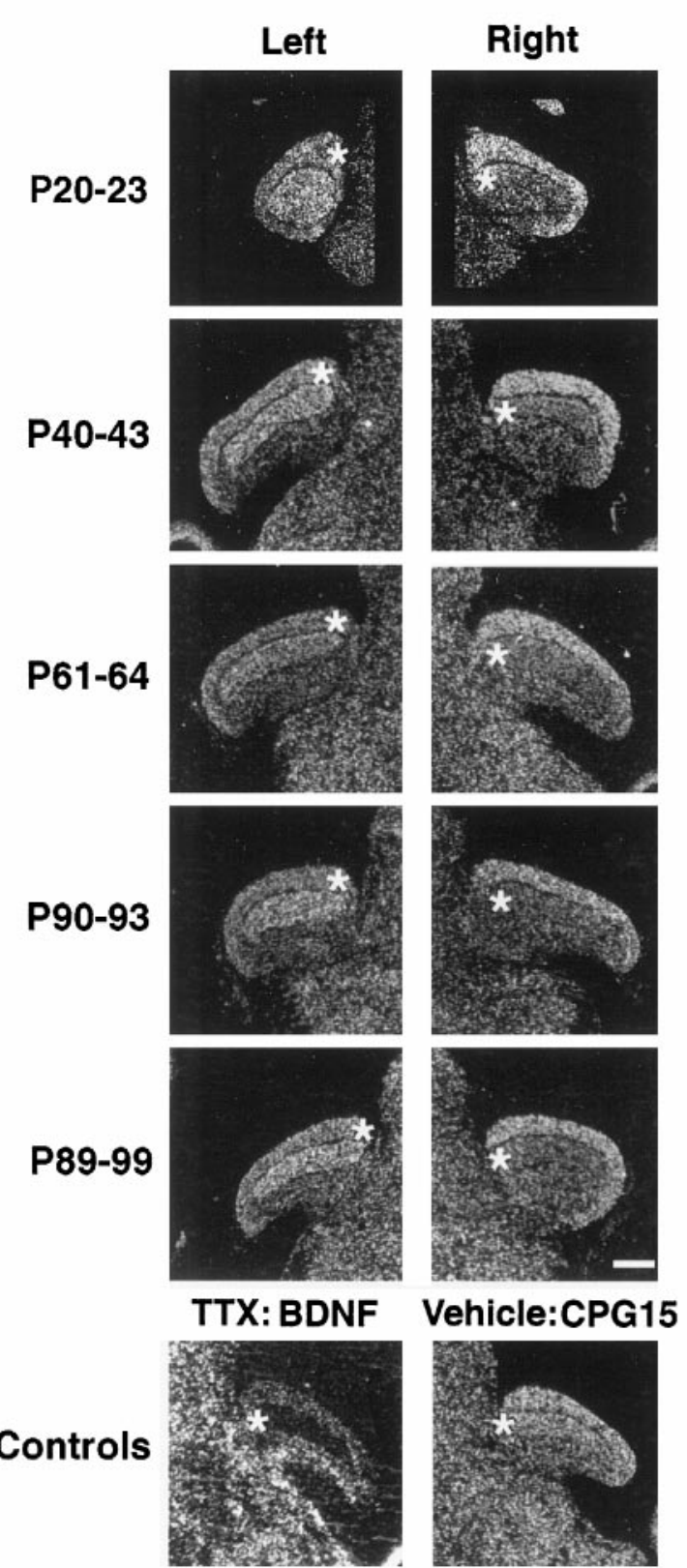

Figure 5. Regulation of feline cpg 15 mRNA levels in the LGN by visual experience. Monocular activity blockade was maintained for the indicated times by injection of TTX into the posterior chamber of the right eye. Dark-field photomicrographs of selected in situ hybridization results. An asterisk indicates the eye-specific LGN layer receiving synaptic input from the treated eye (laver $A$ on the left, contralateral to the blocked eye, and layer $A 1$ on the right, ipsilateral to the blocked eye). Controls (LGNs ipsilateral to the injected eye; treatment was from P38 to P48) show a dramatic decrease in BDNF mRNA in layer A1, confirming the effectiveness of the activity blockade; no decrease is observed in feline cpg 15 mRNA levels when vehicle alone is injected. All sections are in the coronal plane. Medial is toward the center of the figure (except for the BDNF control, in which medial is left), and dorsal is up. Scale bar, $1 \mathrm{~mm}$.

a distance within layer 2/3 and derived its spatial frequency (Fig. 7 , bottom). The measured frequency, $\sim 1 \mathrm{~mm}$, corresponds well with the width of ocular dominance columns assessed either anatomically (LeVay et al., 1978; Anderson et al., 1988) or physiologically (Shatz and Stryker, 1978; Hubener et al., 1997). Similar 
LGN Contralateral to Blocked Eye:A/A1 $\longrightarrow$

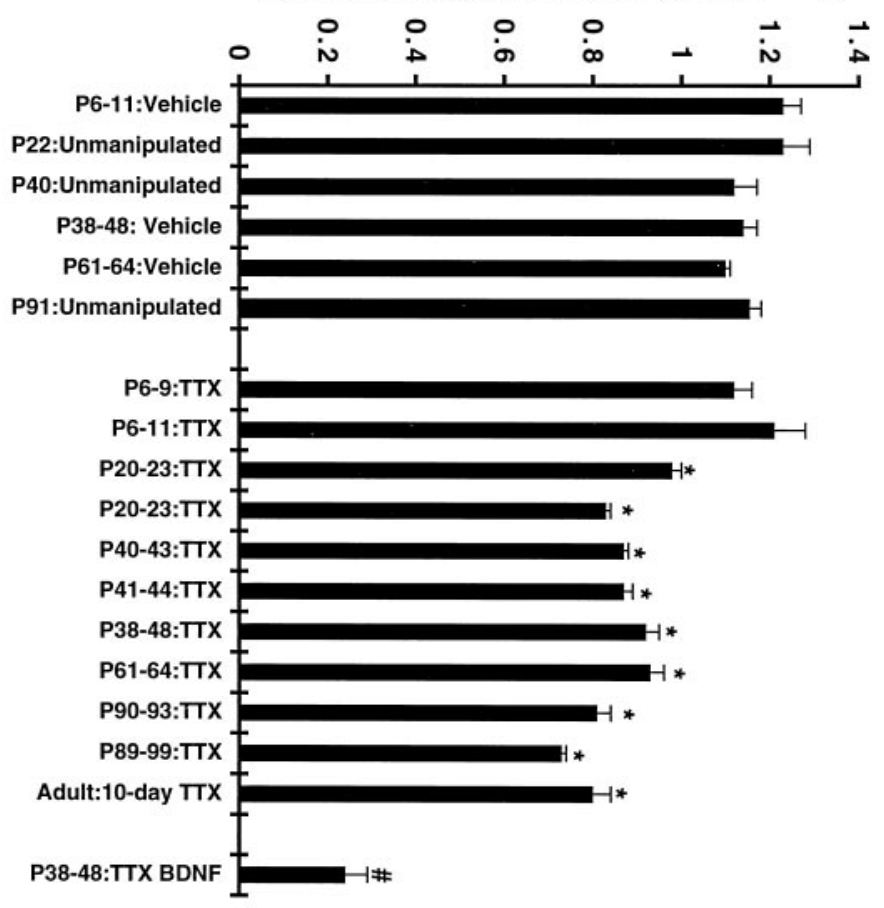

Figure 6. Quantitation of feline cpg15 mRNA regulation in the LGN after monocular blockade. Data are presented for the left LGN, i.e., contralateral to the blocked eye. An index of activity regulation of feline cpg15 mRNA expression was obtained by dividing signal obtained in the eye-specific layer corresponding to the treated eye $(A)$ by that obtained in the control layer (A1) (see Materials and Methods). Each column represents the mean \pm SEM for three to five determinations from two to three independent animals. Asterisks indicate feline cpg15 ratios that are significantly different from controls shown on the left $(p<0.01)$. The P38-P48 BDNF $A / A 1$ ratio (number symbol) is significantly different from all other ratios $(p<0.001)$. The results indicate that feline cpg15 mRNA levels in the LGN are specifically regulated by visual experience after P20 and into adulthood. Analysis of data for the LGN ipsilateral to the injected eye (data not shown, but see Fig. 5) resulted in identical conclusions.

results were obtained after monocular blockades at either P61P64 or P90-P92, well after ODC formation in layer 4 is complete but still during times when monocular eye closure can cause modest physiological shifts in ocular dominance outside of layer 4 (Daw et al., 1992) (see Discussion). Note that no such regular periodicity in signal was observed when the analysis was performed on visual cortex from an animal monocularly treated with vehicle (P61-P64:Vehicle; Fig. 7, bottom, D). These data indicate that cpg15 expression in superficial cortical layers is sensitive to TTX-mediated activity blockade not only during the critical period for geniculocortical axon segregation in layer 4 but also afterward in the mature primary visual cortex.

\section{DISCUSSION}

Here we have explored a possible role for $\operatorname{cpg} 15$ in the structural remodeling of visual system connections by examining its developmental and activity-dependent regulation in the cat's visual system. A major finding is that regulation of cpg15 by electrical activity is a dynamic property that changes during development. Expression in the LGN is highest prenatally during the period of RGC axon segregation into eye-specific layers but is unaffected by TTX-induced action potential blockade at these times. Activityindependent expression in the LGN remains high during the early postnatal period when layer 4 neurons in visual cortex begin elaborating their dendritic arbors (Meyer and Ferres-Torres, 1984). Activity-dependent regulation of cpg15 mRNA levels appears in the LGN only later, coincident with a decline in expression and the onset of LGN axon segregation into ODCs in layer 4 of visual cortex. In contrast, expression of cpg15 in layer 4 neurons-the synaptic targets of LGN axons-is low at all ages examined and not regulated by neural activity. In the Xenopus retinotectal system, CPG15 protein is concentrated in RGC axons at developmental stages when target tectal cell dendritic growth is sensitive to CPG15 expression (Nedivi et al., 1998). Taken together, these observations are consistent with a role for CPG15 in axon terminals promoting dendritic growth in postsynaptic target neurons. We suggest that CPG15 supplied by LGN neurons acts to promote dendritic arbor growth first in subplate neurons and subsequently in layer 4 cortical partners. At early stages CPG15 supplies are abundant and activity independent, but as maturation progresses they become limited and activity dependent, consistent with a role in coordinating the final rearrangements of pre- and postsynaptic elements that are driven by activity-dependent competition.

In contrast to the LGN, in the visual cortex cpg15 mRNA levels are undetectable until early postnatal times. cpg 15 expression then appears in layers $2 / 3$ and $5 / 6$, where it progressively increases until reaching adult levels around P40. Little, if any, expression is detected in layer 4 until P40, when LGN axons have almost completely segregated from each other into ODCs (LeVay et al., 1978); at this age and thereafter, low levels of signal can be observed that are maintained in the adult. Although the segregation of input according to eye preference is most complete in layer 4 (Hubel and Wiesel, 1972; Wiesel et al., 1974; Shatz et al., 1977), neurons in other layers also acquire a certain degree of eye preference by virtue of intracortical connections. This preference can be seen in the system of physiologically defined ODCs present in all cortical layers (Hubel and Wiesel, 1977; Crair et al., 1998). Our observation here that monocular TTX injections lead to regulation of cpg15 expression in alternating patches within layers $2 / 3$ at P40 and thereafter and the periodicity of expression $(\sim 1 \mathrm{~mm})$ are both consistent with downregulation of cpg15 expression within ODCs representing the blocked eye. In the cat visual system, the period of susceptibility to the physiological effects of monocular eye closure in layers $2 / 3$ extends far longer than that in layer 4 , and shifts in ocular dominance after eye closure can be detected physiologically even at 6 months postnatally (Daw et al., 1992). The activity-dependent regulation of cpg15 expression in layers $2 / 3$ coincides well with this well known period of experience-dependent synaptic plasticity and also with the fact that the horizontal connections made by layer $2 / 3$ neurons can undergo long-term facilitation (Hirsch and Gilbert, 1993) and perhaps structural changes (Darian-Smith and Gilbert, 1994). Thus as with geniculocortical connections at earlier ages, here too cpg15 expression and modulation by neural activity are consistent with a presynaptic role for this molecule in activity-dependent remodeling of intracortical connections.

It is important to note that the TTX-insensitive component of cpg15 expression, observed here at early ages, may represent expression that can be regulated by forms of activity that are independent of voltage-gated sodium channels. There is evidence that synaptic activity can influence dendritic arbor development in the absence of sodium-dependent action potentials. In studies in which TTX and glutamate receptor blockers were tested in parallel, in some conditions APV had a strong effect on dendritic 

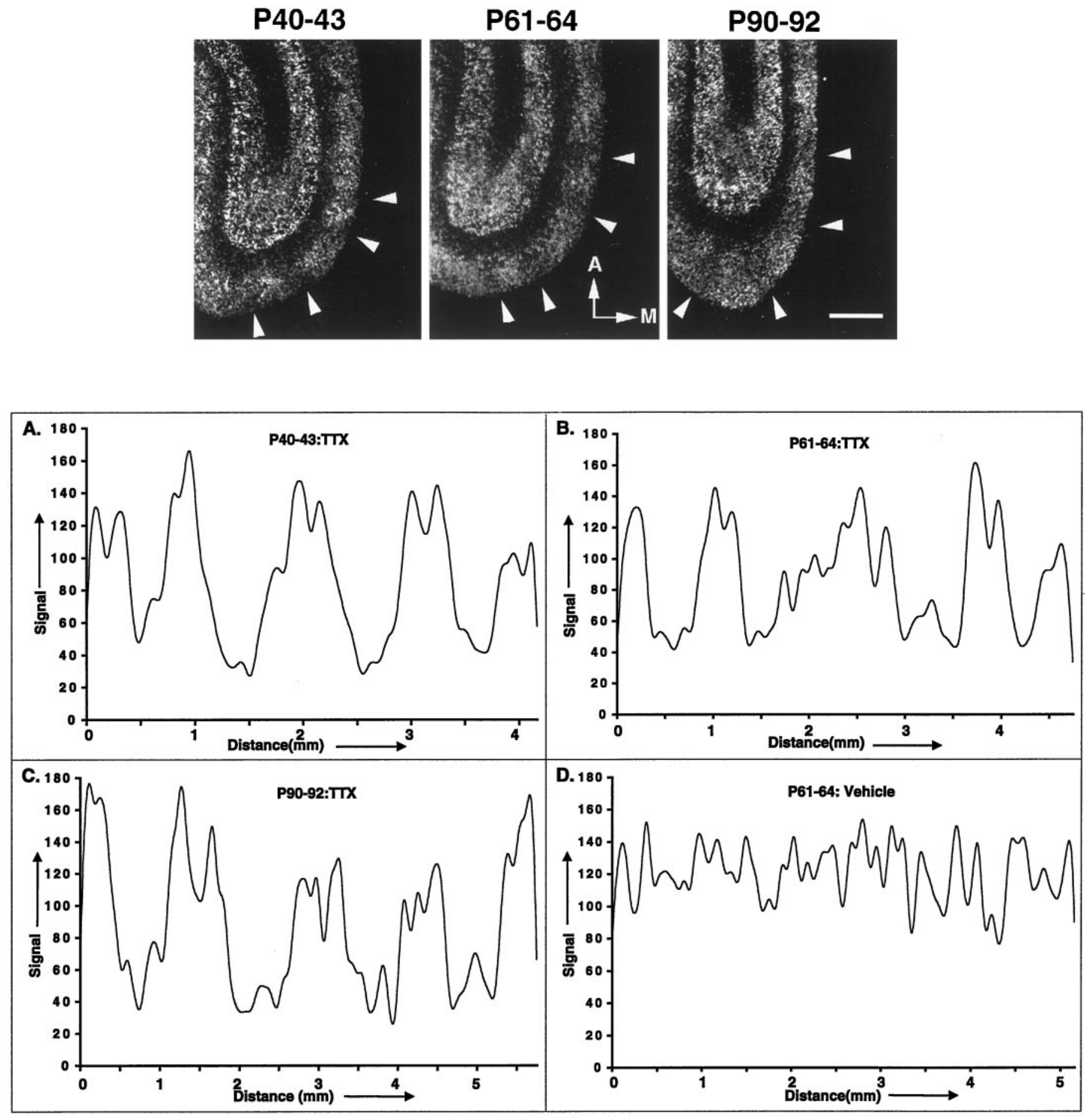

Figure 7. Activity regulation of feline cpg15 in primary visual cortex. Top, After monocular activity blockade for the indicated times, horizontal sections through the visual cortex, optimal for viewing ODCs, were prepared and analyzed by in situ hybridization. Results are presented in dark-field optics. Note the periodicity of signal intensity, with several regions of decreased signal indicated by arrowheads on each panel. A, Anterior. $M$, medial. Scale bar, 1 $\mathrm{mm}$. Bottom, Signal intensity was quantified in the superficial layers (described in Materials and Methods) and found to have a spatial frequency of $\sim 1$ $\mathrm{mm}$, as would be expected if the periodicity observed corresponds to inputs from the control (higher signal) and activity-blocked (lower signal) eyes and therefore ocular dominance columns. Note that no such regular periodicity in signal was observed when the analysis was performed on visual cortex from an animal monocularly treated with vehicle from P61 to P64 (D).

branch dynamics, whereas TTX had no detectable influence (McAllister et al., 1996; Rajan and Cline, 1998). Activation of gene expression by increased intracellular calcium may also be generated by alternative mechanisms to synaptic transmission such as $\mathrm{Ca}^{+2}$ influx through voltage-gated calcium channels. At early developmental times, spontaneous activation of one or a few cells can generate a synchronous rise of intracellular calcium in domains of coactive cortical neurons, even in the presence of 
TTX (Yuste et al., 1995). In view of these considerations, we can only conclude that $\mathrm{Na}^{+}$-dependent action potentials are not required for cpg15 expression at early times in development, whereas at later times they are required.

Gene expression studies show that only a fraction of genes tested, including many that are regulated by seizure activity in the adult, can also be regulated by sodium action potential activity during visual system development (Corriveau et al., 1998). Among these genes, developmental patterns of regulation and expression vary widely (Worley et al., 1990; Castren et al., 1992; Yamagata et al., 1993, 1994a,b; Robner et al., 1994; Schoups et al., 1995; Nedivi et al., 1996; Tsui et al., 1996; Corriveau et al., 1998). This observation suggests that regulation of gene expression by visual system activity is implemented at the transcriptional level on a gene-by-gene basis, in a way that is relevant to the function of each specific gene. Studies of regulated expression of an individual gene such as this one on cpg15 may therefore provide predictions as to its mechanism of action.

We propose a general model in which CPG15 is supplied by the presynaptic neuron, thereby influencing dendritic growth of its postsynaptic partner. During early development, high levels of cpg15 expression may be permissive for rapid dendritic growth in a manner independent of sodium action potentials. This suggestion is consistent both with previous studies demonstrating that early dendritic growth is relatively insensitive to TTX activity blockade (Dalva et al., 1994) and with the observation that overexpression of CPG15 promotes the growth of tectal cell dendrites (Nedivi et al., 1998). After the initial circuitry of neuronal connections has been established by activity-independent mechanisms and neurons have laid down the basic structure of their dendritic arbor, we propose that activity-dependent regulation comes into play. Stabilization, maintenance, and plasticity of specific synaptic connections become the prominent themes during the final transition of the developing nervous system to its mature sets of connections. At this developmental time there is a decline in constitutive cpg15 expression in the LGN, accompanied by emergence of an activity-dependent regulation that persists into adulthood. At this point the balance between activityindependent levels of cpg15 expression in all neurons and the additional activity-dependent cpg15 expression present in active neurons may determine the extent to which synaptic connections are merely maintained versus strengthened via addition of new neuronal processes. The advent of an activity-dependent mode of cpg15 regulation could allow local increases in CPG15 levels only at synapses of active presynaptic neurons, thus permitting the specific changes in dendritic arbor structure that are associated with synaptic plasticity. This model could resolve some of the inconsistencies reported for the effects of activity on dendritic structure because activity blockade at different developmental times would have different effects on the induction of genes that influence dendritic growth such as cpg15. Direct proof for this model will require manipulations of $c p g 15$ expression and exploration of the consequent effects on synaptic plasticity.

It is surprising that cpg15 expression is regulated by visual activity in the mature LGN, long after the critical period for development of the geniculocortical synapse comes to a close. At first glance, this result appears to weaken the argument that CPG15 may be involved in activity-dependent developmental plasticity. However, it is important to remember that the critical period for development of the geniculocortical projection has been defined anatomically in terms of axonal, and not dendritic, morphological changes that can be induced by alterations in electrical activity. Because our model proposes that CPG15 on LGN axons affects the dendritic morphology of postsynaptic layer 4 neurons, the finding that cpg15 expression is activity-regulated in the mature LGN does not necessarily run counter to previous findings demonstrating that activity-dependent LGN axonal arbor rearrangements are confined to the critical period. In fact, the persistent regulation of cpg15 predicts that activity-dependent changes might occur locally on the dendrites or spines of layer 4 neurons (as well as layer 2/3 neurons) well after it is no longer possible to induce large-scale LGN axon terminal rearrangements. It remains to be shown directly whether dendrites or spines of layer 4 neurons in mature animals can respond to changes in activity with structural rearrangements. Two-photon imaging of CA1 neurons in developing rat hippocampal slices has shown local and rapid changes in dendritic structures in response to synaptic activity (Engert and Bonhoeffer, 1999; Maletic-Savatic et al., 1999). Such technology might be extended to mature cortical slices or to an in vivo mammalian system.

Models of afferent segregation into eye-specific domains in the visual system generally require coordinate interactions between pre- and postsynaptic partners (Willshaw and Von der Malsburg, 1976; Whitelaw and Cowan, 1981; Miller et al., 1989). Anatomical studies provide evidence of such coordinate growth, in that dendritic arbors often respect eye-specific boundaries defined by their presynaptic partners (Katz and Constantine-Paton, 1988; Katz et al., 1989; Kossel et al., 1995). Visual manipulations that alter the termination pattern of afferent arbors can cause a corresponding shift in dendritic arbor structure (Tieman and Hirsch, 1982; Kossel et al., 1995). Our results suggest that in the mammalian visual system, CPG15 may be a molecular mediator that can coordinate growth of postsynaptic dendritic partners with their presynaptic counterparts, during both early activity-independent and later activity-dependent development of synaptic connectivity.

\section{REFERENCES}

Anderson PA, Olavarria J, Van Sluyters RC (1988) The overall pattern of ocular dominance bands in cat visual cortex. J Neurosci 8:2183-2200.

Antonini A, Stryker MP (1993) Development of individual geniculocortical arbors in cat striate cortex and effects of binocular impulse blockade. J Neurosci 13:3549-3573.

Bodnarenko SR, Chalupa LM (1993) Stratification of ON and OFF ganglion cell dendrites depends on glutamate-mediated afferent activity in the developing retina. Nature 364:144-146.

Campbell G, Ramoa AS, Stryker MP, Shatz CJ (1997) Dendritic development of retinal ganglion cells after prenatal intracranial infusion of tetrodotoxin. Vis Neurosci 14:779-788.

Castren E, Zafra F, Thoenen H, Lindholm D (1992) Light regulates expression of brain-derived neurotrophic factor mRNA in rat visual cortex. Proc Natl Acad Sci USA 89:9444-9448.

Chomczynski P, Sacchi N (1987) Single-step method of RNA isolation by acid guanidinium thiocyanate-phenol-chloroform extraction. Anal Biochem 162:156-159.

Constantine-Paton M, Cline HT, Debski E (1990) Patterned activity, synaptic convergence, and the NMDA receptor in developing visual pathways. Annu Rev Neurosci 13:129-154.

Corriveau RA, Huh GS, Shatz CJ (1998) Regulation of class I MHC gene expression in the developing and mature CNS by neural activity. Neuron 21:505-520.

Crair MC, Gillespie DC, Stryker MP (1998) The role of visual experience in the development of columns in cat visual cortex. Science 279:566-570.

Dalva MB, Ghosh A, Shatz CJ (1994) Independent control of dendritic and axonal form in the developing lateral geniculate nucleus. J Neurosci 14:3588-3602. 
Darian-Smith C, Gilbert CD (1994) Axonal sprouting accompanies functional reorganization in adult cat striate cortex. Nature 368:737-740.

Daw NW, Fox K, Sato H, Czepita D (1992) Critical period for monocular deprivation in the cat visual cortex. J Neurophysiol 67:197-202.

Dubin MW, Stark LA, Archer SM (1986) A role for action-potential activity in the development of neuronal connections in the kitten retinogeniculate pathway. J Neurosci 6:1021-1036.

Engert F, Bonhoeffer T (1999) Dendritic spine changes associated with hippocampal long-term synaptic plasticity. Nature 399:66-70.

Goodman CS, Shatz CJ (1993) Developmental mechanisms that generate precise patterns of neuronal connectivity. Cell 10:77-98.

Guillery RW (1972) Binocular competition in the control of geniculate cell growth. J Comp Neurol 144:117-130.

Hata Y, Tsumoto T, Stryker MP (1999) Selective pruning of more active afferents when cat visual cortex is pharmacologically inhibited. Neuron 22:375-381.

Hirsch JA, Gilbert CD (1993) Long-term changes in synaptic strength along specific intrinsic pathways in the cat visual cortex. J Physiol (Lond) 461:247-262.

Hubel DH, Wiesel TN (1963) Effects of visual deprivation on morphology and physiology of cells in the cat's lateral geniculate body. J Neurophysiol 26:978-993.

Hubel DH, Wiesel TN (1970) The period of susceptibility to the physiological effects of unilateral eye closure in kittens. J Physiol (Lond) 206:419-436.

Hubel DH, Wiesel TN (1972) Laminar and columnar distribution of geniculo-cortical fibres in the macaque monkey. J Comp Neurol 146:421-450.

Hubel DH, Wiesel TN (1977) Functional architecture of macaque monkey visual cortex. Proc R Soc Lond [Biol] 198:1-59.

Hubener M, Shoham D, Grinvald A, Bonhoeffer T (1997) Spatial relationships among three columnar systems in cat area 17. J Neurosci 17:9270-9284.

Kandel ER, O'Dell TJ (1992) Are adult learning mechanisms also used for development? Science 258: 243-245.

Katz LC, Constantine-Paton M (1988) Relationships between segregated afferents and postsynaptic neurons in the optic tectum of threeeyed frogs. J Neurosci 8:3160-3180.

Katz LC, Shatz CJ (1996) Synaptic activity and the construction of cortical circuits. Science 274:1133-1138.

Katz LC, Gilbert CD, Wiesel TN (1989) Local circuits and ocular dominance columns in monkey striate cortex. J Neurosci 9:1389-1399.

Kossel A, Lowel S, Bolz J (1995) Relationships between dendritic fields and functional architecture in striate cortex of normal and visually deprived cats. J Neurosci 15:3913-3926.

Kossel A, Williams C, Schweizer M, Kater S (1997) Afferent innervation influences the development of dendritic branches and spines via both activity-dependent and nonactivity-dependent mechanisms. J Neurosci 17:6314-6324.

LeVay S, Stryker MP, Shatz CJ (1978) Ocular dominance columns and their development in layer IV of the cat's visual cortex. J Comp Neurol 179:223-244.

LeVay S, Wiesel TN, Hubel DH (1980) The development of ocular dominance columns in normal and visually deprived monkeys. J Comp Neurol 191:1-51.

Link W, Konietzko U, Kauselmann G, Krug M, Schwanke B, Frey U, Kuhl D (1995) Somatodendritic expression of an immediate early gene is regulated by synaptic activity. Proc Natl Acad Sci USA 92:5734-5738.

Lund JS, Holbach SM, Chung W-W (1991) Postnatal development of thalamic recipient neurons in the monkey striate cortex. II. Influence of afferent driving on spine acquisition and dendritic growth of layer $4 \mathrm{C}$ spiny stellate neurons. J Comp Neurol 309:129-140.

Lyford GL, Yamagata K, Kaufmann WE, Barnes CA, Sanders LK, Copeland NG, Gilbert DJ, Jenkins NA, Lanahan A, Worley PF (1995) Arc, a growth factor and activity-regulated gene encodes a novel cytoskeletal-associated protein that is enriched in neuronal dendrites. Neuron 14:433-445.

Maletic-Savatic M, Malinow R, Svoboda K (1999) Rapid dendritic morphogenesis in CA1 hippocampal dendrites induced by synaptic activity. Science 283:923-927.

McAllister AK, Katz LC, Lo DC (1996) Neurotrophin regulation of cortical dendritic growth requires activity. Neuron 17:1057-1064.

McKinney RA, Capogna M, Durr R, Gahwiler BH, Thompson SM
(1999) Miniature synaptic events maintain dendritic spines via AMPA receptor activation. Nat Neurosci 2:44-49.

Meister M, Wong RO, Baylor DA, Shatz CJ (1991) Synchronous bursts of action potentials in ganglion cells of the developing mammalian retina. Science 252:939-943.

Meyer G, Ferres-Torres R (1984) Postnatal maturation of nonpyramidal neurons in the visual cortex of the cat. J Comp Neurol 228:226-244.

Meyer RL (1982) Tetrodotoxin blocks the formation of ocular dominance columns in goldfish. Science 218:589-591.

Miller KD, Keller JB, Stryker MP (1989) Ocular dominance column development: analysis and simulation. Science 245:605-615.

Mooney R, Penn AA, Gallego R, Shatz CJ (1996) Thalamic relay of spontaneous retinal activity prior to vision. Neuron 17:863-874.

Naeve GS, Ramakrishnan M, Rainer K, Hevroni D, Citri Y, Theill LE (1997) Neuritin: a gene induced by neural activity and neurotrophins that promotes neuritogenesis. Proc Natl Acad Sci USA 94:2648-2653.

Nedivi E, Hevroni D, Naot D, Israeli D, Citri Y (1993) Numerous candidate plasticity-related genes revealed by differential cDNA cloning. Nature 363:718-722.

Nedivi E, Fieldust S, Theill L, Hevroni D (1996) A set of genes expressed in response to light in the adult cerebral cortex and regulated during development. Proc Natl Acad Sci USA 93:2048-2053.

Nedivi E, Wu GY, Cline H (1998) Promotion of dendritic growth by CPG15, an activity-induced signaling molecule. Science 281:1863-1866.

Penn AA, Riquelme PA, Feller MB, Shatz CJ (1998) Competition in retinogeniculate patterning driven by spontaneous activity. Science 279:2108-2112.

Qian Z, Gilbert ME, Colicos MA, Kandel ER, Kuhl D (1993) Tissueplasminogen activator is induced as an immediate-early gene during seizure, kindling and long-term potentiation. Nature 361:453-457.

Rajan I, Cline HT (1998) Glutamate receptor activity is required for normal development of tectal cell dendrites in vivo. J Neurosci 18:7836-7846.

Reh T, Constantine-Paton M (1985) Eye-specific segregation requires neural activity in three-eyed Rana pipiens. J Neurosci 5:1132-1143.

Robner S, Kumar A, Witzemann V, Schliebs R (1994) Development of laminar expression of the $\mathrm{m}_{2}$ muscarinic cholinergic receptor gene in rat visual cortex and the effect of monocular visual deprivation. Dev Brain Res 77:55-61.

Rocha M, Sur M (1995) Rapid acquisition of dendritic spines by visual thalamic neurons after blockade of $N$-methyl-D-aspartate receptors. Proc Natl Acad Sci USA 92:8026-8030.

Sambrook J, Fritsch EF, Maniatis T (1989) Molecular cloning: a laboratory manual. New York: Cold Spring Harbor Laboratory.

Schoups AA, Elliott RC, Friedman WJ, Black IB (1995) NGF and BDNF are differentially modulated by visual experience in the developing geniculocortical pathway. Brain Res Dev Brain Res 86:326-334.

Shatz CJ (1983) The prenatal development of the cat's retinogeniculate pathway. J Neurosci 3:482-499.

Shatz CJ (1990) Impulse activity and the patterning of connections during CNS development. Neuron 5:745-756.

Shatz CJ, Kirkwood P (1984) Prenatal development of functional connections in the cat's retinogeniculate pathway. J Neurosci 4:1378-1397.

Shatz CJ, Luskin MB (1986) The relationship between the geniculocortical afferents and their cortical target cells during the development of the cat's primary visual cortex. J Neurosci 6:3655-3668.

Shatz CJ, Stryker MP (1978) Ocular dominance in layer IV of the cat's visual cortex and the effects of monocular deprivation. J Physiol (Lond) 281:267-283.

Shatz CJ, Stryker MP (1988) Prenatal tetrodotoxin infusion blocks segregation of retinogeniculate afferents. Science 242:87-89.

Shatz CJ, Lindstrom SH, Wiesel TN (1977) The distribution of afferents representing the right and left eyes in the cat's visual cortex. Brain Res 131:103-116.

Simmons DM, Arriza JL, Swanson LW (1989) A complete protocol for in situ hybridization of messenger RNAs in brain and other tissues with radiolabeled single-stranded RNA probes. J Histotechnol 12:169-181.

Sretavan DW, Shatz CJ (1986) Prenatal development of retinal ganglion cell axons: segregation into eye-specific layers. J Neurosci 6:234-251.

Sretavan DW, Shatz CJ, Stryker MP (1988) Modification of retinal ganglion cell axon morphology by prenatal infusion of tetrodotoxin. Nature 336:468-471.

Stryker MP, Harris WA (1986) Binocular impulse blockade prevents the 
formation of ocular dominance columns in cat visual cortex. J Neurosci 6:2117-2133.

Tieman SB, Hirsch HVB (1982) Exposure to lines of only one orientation modifies dendritic morphology of cells in the visual cortex of the cat. J Comp Neurol 211:353-362.

Tsui CC, Copeland NG, Gilbert DJ, Jenkins NA, Barnes CA, Worley PF (1996) Narp, a novel member of the pentraxin family, promotes neurite outgrowth and is dynamically regulated by neuronal activity. J Neurosci 16:2463-2478.

Vogel MW, Prittie J (1995) Purkinje cell dendritic arbors in chick embryos following chronic treatments with an $N$-methyl-D-aspartate receptor antagonist. J Neurobiol 26:537-552.

Whitelaw VA, Cowan JD (1981) Specificity and plasticity of retinotectal connections: a computational model. J Neurosci 1:1369-1387.

Wiesel TN, Hubel DH, Lam K (1974) Autoradiographic demonstration of ocular-dominance columns in monkey striate cortex by means of transneuronal transport. Brain Res 79:273-279.

Willshaw DJ, Von der Malsburg C (1976) How patterned neural connections can be set up by self-organization. Proc R Soc Lond [Biol] 194:431-445.
Wong ROL, Chernjavsky A, Smith SJ, Shatz CJ (1995) Early functional neural networks in the developing retina. Nature 374:716-718.

Worley PF, Cole AJ, Murphy TH, Christy BA, Nakabeppu Y, Baraban JM (1990) Synaptic regulation of immediate-early genes in brain. Cold Spring Harb Symp Quant Biol 55:213-222.

Yamagata K, Andreasson KI, Kaufmann WE, Barnes CA, Worley PF (1993) Expression of a mitogen-inducible cyclooxygenase in brain neurons: regulation by synaptic activity and glucocorticoids. Neuron 11:371-386.

Yamagata K, Kaufmann WE, Lanahan A, Papapavlou M, Barnes CA, Andreasson KI, Worley PF (1994a) Egr3/Pilot, a zinc finger transcription factor, is rapidly regulated by activity in brain neurons and colocalizes with Egr1/zif268. Learn Mem 1:140-152.

Yamagata K, Sanders LK, Kaufmann WE, Yee W, Barnes CA, Nathans D, Worley PF (1994b) rheb, a growth factor- and activity-regulated gene, encodes a novel ras-related protein. J Biol Chem 269:16333-16339.

Yuste R, Nelson DA, Rubin WW, Katz LC (1995) Neuronal domains in developing neocortex: mechanisms of coactivation. Neuron 14:7-17. 